\title{
Evaluation of antioxidant potential of two Daphne species ( $D$. gnidioides and $D$. pontica) from Turkey
}

\author{
Murad Aydin Sanda', Gokhan Zengin ${ }^{1 *}$, Abdurrahman Aktumsek', Yavuz Selim Cakmak ${ }^{2}$ \\ ${ }^{1}$ Department of Biology, Science Faculty, Selcuk University, Konya, Turkey; ${ }^{2}$ Deparment of Biotechnology and Molecular Biology, Faculty of \\ Science and Arts, Aksaray University, Aksaray, Turkey
}

\section{A B S T R A C T}

\begin{abstract}
Daphne species have been used traditionally for treatment of several ailments including rheumatism, abscess and diarrhoea. Purpose of present study was to evaluate antioxidant activities of methanol and water extracts of Daphne parts (roots, stems and leaves). Different experimental models including phosphomolydenum, DPPH, $\beta$-carotene/linoleic acid, ferric and cupric reducing power assays were performed to characterize the antioxidant potentials of the extracts. Folin-Ciocalteu and $\mathrm{AlCl}_{3}$ methods were also used to quantify total phenolic and flavonoid content, respectively. D. pontica leaf extract showed high phenolic contents $\left(123.09 \mathrm{mgGAEg}^{-1}\right.$ in methanol and $146.94 \mathrm{mgGAEg}^{-1}$ in water extract) therefore has the strongest antioxidant potential. Present study showed that Daphne extracts (D. gnidioides and $D$. pontica) can be considered as good sources of natural antioxidants for medicinal and food applications.
\end{abstract}

Keywords: Antioxidants; Daphne; Phenolics; Flavonoids; DPPH

\section{INTRODUCTION}

Oxidative stress is defined as the imbalance between production of free radicals and antioxidants. The situation is responsible for causing several diseases including cancer, cardiovascular diseases and neural disorders (Tolluec et al., 2010). Antioxidants are substances present at low concentrations, which significantly inhibit or delay the oxidative process. Besides, playing an important role in physiological systems, antioxidants have been used in food processing to prolong the shelf life of foods, especially those rich in polyunsaturated fats. Therefore, several types of synthetic antioxidants (BHA, BHT, PG or TBHQ) are widely used food industry to prevent lipid oxidation. However, the use of these compounds is restricted due to potential health risks such as carcinogenic (Ito et al., 1986; Kim et al., 2010; Sherwin et al., 1990). Hence, development of novel antioxidants from natural resources continues to arouse great attention, and in recent years, medicinal plants have attracted great attention in the search of natural antioxidants.

The genus Daphne belongs to the family Thymelaceae and is represented by 70 species, of which seven species grow in Turkey. These species are D. gnidioides, D. mezereum, D. mucronata, D. oleoides, D. pontica and D. serica (Tan, 1982). Daphne species are used as folk herbal medicine in many countries for the treatment of several ailments. For example, D.giraldii, D. tangutica, D. retusa and D. koreana are used in China for the treatment of aches and rheumatism, especially for rheumatoid arthritis (Yang, 1991). Fruits of D. mezereum are used for ulcers, rheumatism and skin diseases (Grieve and Leyel, 1967). In Turkey, D. oleoides subsp. oleoides is used as remedy for rheumatism, wound healing and abscess (Sezik et al., 2001). Daphne pontica L. is a shrub grown in the northern Anatolia. Moreover, the stem bark of D. pontica is used against diarrhea (Yesilada et al., 1999). Phytochemical investigations showed that the Daphne species contain several types of natural compounds including flavonoids, coumarins and diterpenoids (Zhang et al., 2006; Zhang et al., 2008). Also, in our previous study (Zengin et al., 2013) antioxidant properties of different extracts of $D$. oleoides subsp. oleoides and D. serica were reported. To the best of our knowledge, no antioxidant investigation has been reported on extracts of $D$. gnidioides and D. pontica parts yet.

The aim of the current study was to investigate the in vitro antioxidant effects of these species in order to determine

\footnotetext{
${ }^{*}$ Corresponding author:

Gokhan Zengin, Department of Biology, Science Faculty, Selcuk University, Konya, Turkey. Tel.: +90 332 223 2781, Fax: +90 332 2410106,

E-mail: gokhanzengin@selcuk.edu.tr
} 
the significance in terms of pharmacological and food industry. For this purpose, two extracts (methanol and water) obtained from roots, stems and leaves of two Daphne species were investigated with different in vitro antioxidant models including phosphomolybdenum, $\mathrm{DPPH}, \beta$-carotene/linoleic acid, ferric and cupric reducing power assays.

\section{MATERIALS AND METHODS}

\section{Plant materials}

Daphne species were collected from different localities in Turkey during vegetation season of 2011. The plants were identified by botanist Dr. M. Aydin Sanda. The voucher specimens were deposited in Selcuk University Education Faculty Herbarium, Konya. The complete list of plant materials with taxonomical information, location and voucher number is given below:

1. Daphne gnidioides Jaub. \& Spach: Antalya: Akseki, Murtiçi, Çukurköy, 673 m, 36S 395817E; 4082048N, Zengin and Sanda 1001.

2. Daphne pontica L.: Bursa: 409 m, 291230.3E; 400951.4N, Zengin and Sanda 1002.

\section{Preparation of the extracts}

All the plant materials (roots, stems and leaves) were dried at room temperature. The dried plant materials were ground to a fine powder using a laboratory mill. Fifteen grams of powdered plant parts were mixed with $250 \mathrm{~mL}$ methanol and extracted in a Soxhlet apparatus for 6-8 h. The extracts were concentrated under vacuum at $40^{\circ} \mathrm{C}$ by using a rotary evaporator. For water extraction, plant parts $(15 \mathrm{~g})$ were heated with $250 \mathrm{ml}$ deionized water for $30 \mathrm{~min}$. The aqueous extracts were filtered and freze dried $\left(-80^{\circ} \mathrm{C}, 48 \mathrm{~h}\right)$. Extracts were stored at $+4^{\circ} \mathrm{C}$ in dark until use.

\section{Chemicals}

Potassium ferricyanide, ferric chloride, Folin-Ciocalteu's phenol reagent, trichloroacetic acid, butylated hydroxytoluene (BHT), butylated hydroxyanisole (BHA) and methanol were purchased from Merck (Darmstadt, Germany). 2,2-diphenyl-1-picrylhydrazyl (DPPH), $\beta$-carotene, linoleic acid and Tween 40 were purchased from Sigma Chemical Co. (Sigma-Aldrich GmbH, Sternheim, Germany). All other chemicals and solvents were analytical grade.

\section{Assay for total phenolics}

Total phenolic constituents of the extracts were determined by employing the methods given in the literature (Slinkard and Singleton, 1977) involving Folin-Ciocalteu reagent and gallic acid as standard. $1 \mathrm{~mL}$ of extract solution containing $2 \mathrm{mg}$ was added to a volumetric flask. $45 \mathrm{~mL}$ distilled water and $1 \mathrm{~mL}$ Folin-Ciocalteu reagent was added and flask was shaken vigorously. After $3 \mathrm{~min}, 3 \mathrm{~mL}$ of $\mathrm{Na}_{2} \mathrm{CO}_{3}$ $(2 \%)$ solution was added and the mixture was allowed to stand for $2 \mathrm{~h}$ with intermittent shaking. Absorbance was measured at $760 \mathrm{~nm}$ (Shimadzu-UV1800). The total phenolic content was determined as gallic acid equivalents (mg GAE g ${ }^{-1}$ extract).

\section{Assay for total flavonoids}

The total flavonoid content in extracts was determined spectrophotometrically according to Arvouet-Grand et al. (1994). Briefly, $1 \mathrm{~mL}$ of $2 \%$ aluminium trichloride $\left(\mathrm{AlCl}_{3}\right)$ methanolic solution was mixed with the same volume of extract solution (at $2 \mathrm{mg} \mathrm{mL}^{-1}$ concentration). The absorbance values of the reaction mixtures were determined at $415 \mathrm{~nm}$ after $10 \mathrm{~min}$ duration against a blank. Rutin was used as the standard and the total flavonoids content of the extracts was expressed as $\mathrm{mg}$ rutin equivalents per gram of extract (mg RE $\mathrm{g}^{-1}$ extract).

Evaluation of total antioxidant capacity by phosphomolybdate assay

The total antioxidant capacities of extracts were evaluated by phosphomolybdenum method according to Prieto et al. (1999). $0.3 \mathrm{~mL}$ of sample extracts $\left(2 \mathrm{mg} \mathrm{mL}^{-1}\right)$ were combined with $3 \mathrm{~mL}$ reagent solution $(0.6 \mathrm{M}$ sulfuric acid, $28 \mathrm{mM}$ sodium phosphate and $4 \mathrm{mM}$ ammonium molybdate). The tubes containing the reaction solution were incubated at $95{ }^{\circ} \mathrm{C}$ for $90 \mathrm{~min}$ and the absorbance of the solution was measured at $695 \mathrm{~nm}$ against a blank. The antioxidant capacity of extracts was expressed as equivalents of ascorbic acid (mg $\mathrm{AE} \mathrm{g}^{-1}$ extract).

\section{Scavenging activity on DPPH}

The hydrogen atoms or electrons donating ability of the corresponding extracts and some pure compounds were measured from the bleaching of purple colored methanol solution of DPPH. The effect of the extracts on DPPH radical was estimated according to Sarikurkcu et al. (2009). $1 \mathrm{~mL}$ of various concentrations of the methanolic extract was added to $4 \mathrm{~mL}$ of $0.004 \%$ methanol solution of DPPH. The mixture was shaken vigorously and allowed to stand for $30 \mathrm{~min}$ and the absorbance of the resulting solution was measured at $517 \mathrm{~nm}$. Inhibition was calculated as follows:

$I(\%)=\left(A_{0}-A_{1}\right) / A_{0} \times 100$

Where $A_{0}$ is the absorbance of the control, $A_{1}$ is the absorbance of the extract/standard. $50 \%$ of free radical inhibition $\left(\mathrm{IC}_{50}\right)$ of extract was calculated. The lower the $\mathrm{IC}_{50}$ value indicates high antioxidant capacity.

\section{$\beta$-carotene-Linoleic acid bleaching assay}

In this assay antioxidant capacity was determined by measuring inhibition of the volatile organic compounds and conjugated dienehydroperoxides arising from linoleic 
acid oxidation (Dapkevicius et al., 1998). A stock solution of -carotene-linoleic acid mixture was prepared as follows: $0.5 \mathrm{mg}$-carotene was dissolved in $1 \mathrm{~mL}$ of chloroform (HPLC grade). $25 \mu \mathrm{L}$ linoleic acid and $200 \mathrm{mg}$ Tween 40 were added. Chloroform was completely evaporated using a vacuum evaporator. Then $100 \mathrm{~mL}$ of oxygenated distilled water was added with vigorous shaking; $2.5 \mathrm{~mL}$ of this reaction mixture was transferred to test tubes and $0.35 \mathrm{~mL}$ of the extracts $\left(2 \mathrm{mg} \mathrm{mL}^{-1}\right)$ were added and the emulsion system was incubated for up to $2 \mathrm{~h}$ at $50 \mathrm{C}$. The same procedure was repeated with the positive control BHT, BHA and a blank. After this incubation period, absorbance of the mixtures was measured at $490 \mathrm{~nm}$. Measurement of absorbance was continued until the color of $\beta$-carotene disappeared. The bleaching rate $(\mathrm{R})$ of -carotene was calculated according to Eq. (1).

$R=\ln (a / b) / t$

Where, $\ln =$ natural $\log , a=$ absorbance at time 0 , $b=$ absorbance at time $t(120 \mathrm{~min})$. The antioxidant activity (AA) was calculated in terms of percent inhibition relative to the control using Eq. (2).

$$
A A=\left[\left(\mathrm{R}_{\text {Control }}-\mathrm{R}_{\text {Sample }}\right) / \mathrm{R}_{\text {Controt }}\right] \times 100
$$

Antioxidative activities of the extracts were compared with those of BHT and BHA at $2.0 \mathrm{mg} / \mathrm{ml}$.

\section{Reducing power activity (Iron (III) to iron (II) reduction)} The ferric reducing power method was applied with slight modifications of the method of Oyaizu (1986). Various concentrations of the extracts $(2.5 \mathrm{~mL})$ were mixed with $2.5 \mathrm{~mL}$ of $0.2 \mathrm{M}$ phosphate buffer (pH 6.6) and $2.5 \mathrm{~mL}$ of $1 \%$ potassium ferricyanide. The mixture was incubated at $50^{\circ} \mathrm{C}$ for $20 \mathrm{~min}$. After $2.5 \mathrm{~mL}$ of $10 \%$ trichloroacetic acid was added. $2.5 \mathrm{~mL}$ of the reaction mixture was mixed with $2.5 \mathrm{~mL}$ distilled water and $0.5 \mathrm{~mL}$ of $0.1 \%$ ferric chloride. The solution absorbance was measured at $700 \mathrm{~nm}$. The reducing power of samples increased with the absorbance value. The same procedure was applied with BHA and BHT.

\section{Cupric ion reducing antioxidant capacity (CUPRAC} assay)

The cupric ion reducing capacity of extracts was determined according to the method of Apak et al. (2006). $1 \mathrm{~mL}$ each of $10 \mathrm{mM} \mathrm{CuCl}, 7.5 \mathrm{mM}$ neocuproine, and $\mathrm{NH}_{4}$ Ac buffer (1 M, pH 7.0) solutions were added into a test tube. Then, $0.5 \mathrm{~mL}$ different concentrations of the extracts were mixed and total volume was brought up to $4.1 \mathrm{~mL}$ with deionized water. The mixture absorbance was recorded against a blank at $450 \mathrm{~nm}$ after 30 min incubation at room temperature.

\section{RESULTS AND DISCUSSION}

\section{Total phenolic and flavonoid contents}

Leaves of $D$. pontica had the highest level of phenolics in both methanol (123.09 $\mathrm{mgGAE} / \mathrm{g}$ extract) and water extracts (146.94 mgGAEg $^{-1}$ extract) (Table 2). The leaves contained twice the total phenolic content than leaves of $D$. gnidiodies in methanol extracts. The highest total phenolic contents were observed in the water extracts, except for root extracts. Zengin et al. (2013) found high variability in the polyphenol content of different extracts from two Daphne taxa (D. serica and $D$. oleiodes subsp. oleoides), with values ranging from $3.18 \mathrm{mgGAEg}^{-1}$ extract in D. oleoides subsp. oleoides hexan extract to $391.97 \mathrm{mgGAEg}^{-1}$ extract in D. oleoides subsp. oleoides ethanol extract. Finally, ethanol extracts from aerial parts of two Daphne species possessed the highest level phenolics in the extracts. Similarly, many literatures indicated that amount of total phenolic is greatly depending on the extraction solvent use (Bekir et al., 2013; Fernandez-Agullo et al., 2013) .

Amounts of total flavonoids were higher in methanol extracts than in water extracts (Table 2). The values varied from $3.25 \mathrm{mgREg}^{-1}$ in water extract of leaves of $D$. gnidioides to $91.22 \mathrm{mgREg}^{-1}$ in methanol extract of leaves of D. pontica. Leaf extracts showed a much higher total flavonoid concentration than the rest of the parts. These values are lower than those found by Zengin et al. (2013) in ethanol

Table 1: Total phenolic, flavonoid and antioxidant capacity (by phosphomolybdenum assay) in methanolic and water extracts from different parts of two Daphne species

\begin{tabular}{|c|c|c|c|c|c|c|c|}
\hline \multirow[t]{2}{*}{ Solvent } & \multirow[t]{2}{*}{ Assays } & \multicolumn{3}{|c|}{ D. gnidioides } & \multicolumn{3}{|c|}{ D. pontica } \\
\hline & & Roots & Stems & Leaves & Roots & Stems & Leaves \\
\hline \multirow[t]{3}{*}{ Methanol } & TPC & $91.72 \pm 2.12^{*}$ & $86.85 \pm 5.47$ & $63.20 \pm 0.14$ & $91.57 \pm 1.77$ & $60.64 \pm 2.06$ & $123.09 \pm 3.62$ \\
\hline & TFC & $49.81 \pm 0.47$ & $30.72 \pm 0.12$ & $91.22 \pm 12.77$ & $11.11 \pm 0.90$ & $42.49 \pm 0.27$ & $79.40 \pm 0.20$ \\
\hline & TAC & $262.18 \pm 8.64$ & $226.29 \pm 5.34$ & $119.62 \pm 9.74$ & $254.29 \pm 18.54$ & $237.96 \pm 3.61$ & $276.62 \pm 0.47$ \\
\hline \multirow[t]{3}{*}{ Water } & TPC & $89.76 \pm 0,07$ & $110.99 \pm 7.53$ & $92,77 \pm 1.35$ & $76.15 \pm 2.84$ & $76.61 \pm 4.76$ & $146.94 \pm 4.97$ \\
\hline & TFC & $8.50 \pm 0.01$ & $3.25 \pm 0.59$ & $33.58 \pm 1.06$ & $5.22 \pm 0.08$ & $8.11 \pm 0.86$ & $46.83 \pm 0.08$ \\
\hline & TAC & $503.84 \pm 3.46$ & $512.07 \pm 0.62$ & $340.18 \pm 17.13$ & $624.07 \pm 17.28$ & $572.84 \pm 18.70$ & $682.73 \pm 19.80$ \\
\hline
\end{tabular}

TPC: Total phenolic content (mgGAE g ${ }^{-1}$ extract), TFC: Total flavonoid content (mgRE $\mathrm{g}^{-1}$ extract), TAC: Total antioxidant capacity by phosphomolybdenum assay (mgAE g-1 extract). ${ }^{*}$ Values expressed are means $\pm S$.D. of three parallel measurements 
Sanda, et al.: Antioxidant potential of two Daphne species from Turkey

Table 2: Absorbances obtained from reducing power assays for methanolic and water extracts of different parts of two Daphne species

\begin{tabular}{|c|c|c|c|c|c|c|c|c|c|}
\hline \multirow[t]{2}{*}{ Solvent } & \multirow{2}{*}{$\begin{array}{l}\text { Concentration } \\
\left(\mathrm{mg} \mathrm{mL}^{-1}\right)\end{array}$} & \multicolumn{3}{|c|}{ D. gnidioides } & \multicolumn{3}{|c|}{ D. pontica } & \multicolumn{2}{|c|}{ Syntethic antioxidants } \\
\hline & & Roots & Stems & Leaves & Roots & Stems & Leaves & BHA & BHT \\
\hline \multicolumn{10}{|l|}{ Ferric } \\
\hline \multirow[t]{4}{*}{ Methanol } & 0.2 & $0.327 \pm 0.01^{*}$ & $0.153 \pm 0.02$ & $0.283 \pm 0.04$ & $0.502 \pm 0.06$ & $0.291 \pm 0.013$ & $0.670 \pm 0.01$ & $2.225 \pm 0.092$ & $1.827 \pm 0.005$ \\
\hline & 0.4 & $0.664 \pm 0.01$ & $0.357 \pm 0.02$ & $0.645 \pm 0.01$ & $1.022 \pm 0.044$ & $0.610 \pm 0.018$ & $1.627 \pm 0.07$ & - & - \\
\hline & 1 & $1.480 \pm 0.07$ & $0.847 \pm 0.03$ & $1.402 \pm 0.10$ & $2.278 \pm 0.046$ & $1.362 \pm 0.189$ & $3.101 \pm 0.263$ & - & - \\
\hline & 0.2 & $0.182 \pm 0.03$ & $0.138 \pm 0.01$ & $0.093 \pm 0.02$ & $0.203 \pm 0.01$ & $0.254 \pm 0.01$ & $0.698 \pm 0.01$ & - & - \\
\hline \multirow[t]{2}{*}{ Water } & 0.4 & $0.457 \pm 0.052$ & $0.392 \pm 0.04$ & $0.311 \pm 0.01$ & $0.591 \pm 0.07$ & $0.693 \pm 0.05$ & $1.642 \pm 0.05$ & - & - \\
\hline & 1 & $0.870 \pm 0.01$ & $0.774 \pm 0.04$ & $0.616 \pm 0.06$ & $1.00 \pm 0.04$ & $1.196 \pm 0.02$ & $3.010 \pm 0.01$ & - & - \\
\hline \multicolumn{10}{|l|}{ Cupric } \\
\hline \multirow[t]{4}{*}{ Methanol } & 0.2 & $0.483 \pm 0.081$ & $0.503 \pm 0.120$ & $0.497 \pm 0.113$ & $0.459 \pm 0.083$ & $0.269 \pm 0.034$ & $0.631 \pm 0.026$ & $3.508 \pm 0.192$ & $3.398 \pm 0.037$ \\
\hline & 0.4 & $1.010 \pm 0.042$ & $0.909 \pm 0.051$ & $1.066 \pm 0.134$ & $0.941 \pm 0.026$ & $0.607 \pm 0.025$ & $1.338 \pm 0.084$ & - & - \\
\hline & 1 & $2.103 \pm 0.250$ & $1.930 \pm 0.226$ & $2.388 \pm 0.088$ & $2.075 \pm 0.030$ & $1.422 \pm 0.071$ & $3.007 \pm 0.158$ & - & - \\
\hline & 0.2 & $0.469 \pm 0.021$ & $0.440 \pm 0.010$ & $0.452 \pm 0.010$ & $0.396 \pm 0.013$ & $0.347 \pm 0.01$ & $1.015 \pm 0.051$ & - & - \\
\hline \multirow[t]{2}{*}{ Water } & 0.4 & $0.781 \pm 0.010$ & $0.818 \pm 0.030$ & $0.857 \pm 0.021$ & $0.787 \pm 0.010$ & $0.697 \pm 0.035$ & $2.007 \pm 0.035$ & - & - \\
\hline & 1 & $1.878 \pm 0.158$ & $1.835 \pm 0.010$ & $1.896 \pm 0.057$ & $1.874 \pm 0.028$ & $1.657 \pm 0.030$ & $3.971 \pm 0.021$ & - & - \\
\hline
\end{tabular}

${ }^{*}$ Values expressed are means \pm S.D. of three parallel measurements

extracts of $D$. oleides subsp. oleoides $\left(94.17 \mathrm{mgREg}^{-1}\right)$ and D. serica $\left(180.19 \mathrm{mgREg}^{-1}\right)$. These differences probably can be caused by several factors such as extraction procedures, climatic conditions. According to our knowledge, there is very little information on the total phenolic and flavonoid content of Thymelaeaceae species. From a study of antioxidant activity of Thymela birsuta performed by Akrout et al. (2010), total phenolic and flavonoid content was found to $463.21 \mathrm{mgGAEg}^{-1}$ and $36.80 \mathrm{mgREg}^{-1}$ for $50 \%$ ethanol extracts, respectively.

\section{DPPH free radical scavenging activity}

The concentration of sample required to scavenge $50 \%$ of $\mathrm{DPPH}$ were determined $\left(\mathrm{IC}_{50}\right)$. A lower $\mathrm{IC}_{50}$ value corresponds to a higher antioxidant activity of plant extract. Results are represented in Fig. 1. Water extract of D. pontica with $\mathrm{IC}_{50}$ value of $0.08 \mathrm{mg} \mathrm{mL} \mathrm{m}^{-1}$, showed particularly high free radical scavenging activity. The activities of the six methanol extracts used were in the order: $D$. pontica leaves $>D$. pontica roots $>D$. gnidiodies roots $>D$. pontica stems $>D$. gnidioides stems $>D$. gnidioides leaves. Apparently, methanolic extract of leaves of $D$. gnidioides showed four times lower activity than $D$. pontica which possessed higher concentration of phenolics. In this direction, many studies showed positive strong correlation between free radical scavenging activity and total phenolic content. Among the studied extracts, water extract of $D$. gnidioides have very weak activity with $\mathrm{IC}_{50}$ value of $0.587 \mathrm{mg} \mathrm{mL}^{-1}$. Interestingly, water extracts of root and stems of $D$. gnidioides revealed same free radical scavenging activity. When compared to BHA $\left(\mathrm{IC}_{50}: 0.01 \mathrm{mg} \mathrm{mL}^{-1}\right)$ and BHT $\left(\mathrm{IC}_{50^{\circ}}: 0.02 \mathrm{mg} \mathrm{mL}^{-1}\right)$, all tested extracts was found to be less effective than synthetic antioxidants (data is not shown in Figure 1). Free radical scavenging activity of $D$. oleoides subsp. oleoides and D. serica differed significantly depending on solvent used and the highest activity was reported in ethyl acetate extract of $D$. oleoides subsp. oleoides by Zengin et al. (2013). From these results, the ethyl acetate extract $\left(\mathrm{IC}_{50}: 0.065 \mathrm{mg} \mathrm{mL}^{-1}\right)$ demonstrated more potent free radical scavenging activity than the water extract of $D$. pontica leaves.

Determination total antioxidant capacity by phosphomolybdenum and $\beta$-carotene/linoleic acid bleaching assays

Phosphomolybdenum assay is an alternative to the evaluation of the total antioxidant capacity of plant extracts or compounds. Table 1 showed that both methanol and water extracts of leaves of $D$. pontica has the higher antioxidant than the other extracts $\left(276.62 \mathrm{mgAEg}^{-1}\right.$ for methanol extract, $682.73 \mathrm{mgAEg}^{-1}$ for water extract). The antioxidant activity of water extract of $D$. pontica leaves was 2 -fold higher than that on D. gnidioides leaves. From the results obtained phosphomolybdenum assay it can be concluded that methanol extractshas the poorest activity.

$\beta$-carotene/linoleic acid bleaching method measured the ability of an antioxidant to inhibit lipid peroxidation (Burda and Oleszek, 2011). The results obtained in this assay are an important issue in food processing and preservation. Fig. 2 shows the antioxidant activity of Daphne extracts as measured by the bleaching of $\beta$-carotene. In this assay, the antioxidant capacities in methanolic extracts were higher than water extracts. Methanolic extract of leaves of $D$. pontica was the most effective, with an inhibition value of $89.96 \%$ which close to the activity of the standard commercial antioxidants, BHA (93.37\%) and BHT $(94.32 \%)$. A relationship between the DPPH scavenging ability and $\beta$-carotene bleaching extent was found. In both assays, the polar methanolic extracts (except for D. pontica leaves) showed better antioxidative capacity than water extracts. Accordance with these results, the highest inhibition capacities were obtained from alcoholic extracts 


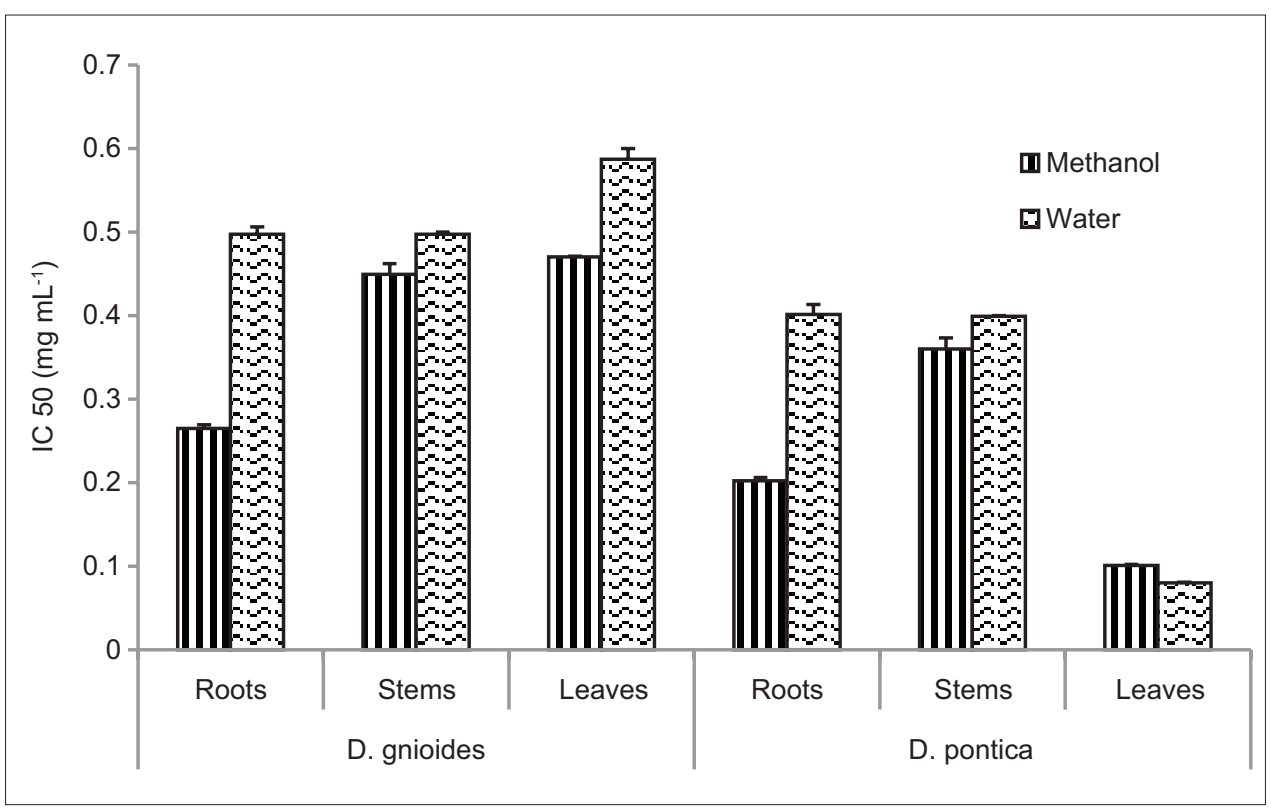

Fig 1. Free radical scavenging activites of methanolıc and water extracts of different parts of two Daphne species by DPPH assay. (Values expressed are means \pm S.D. of three parallel measurements).

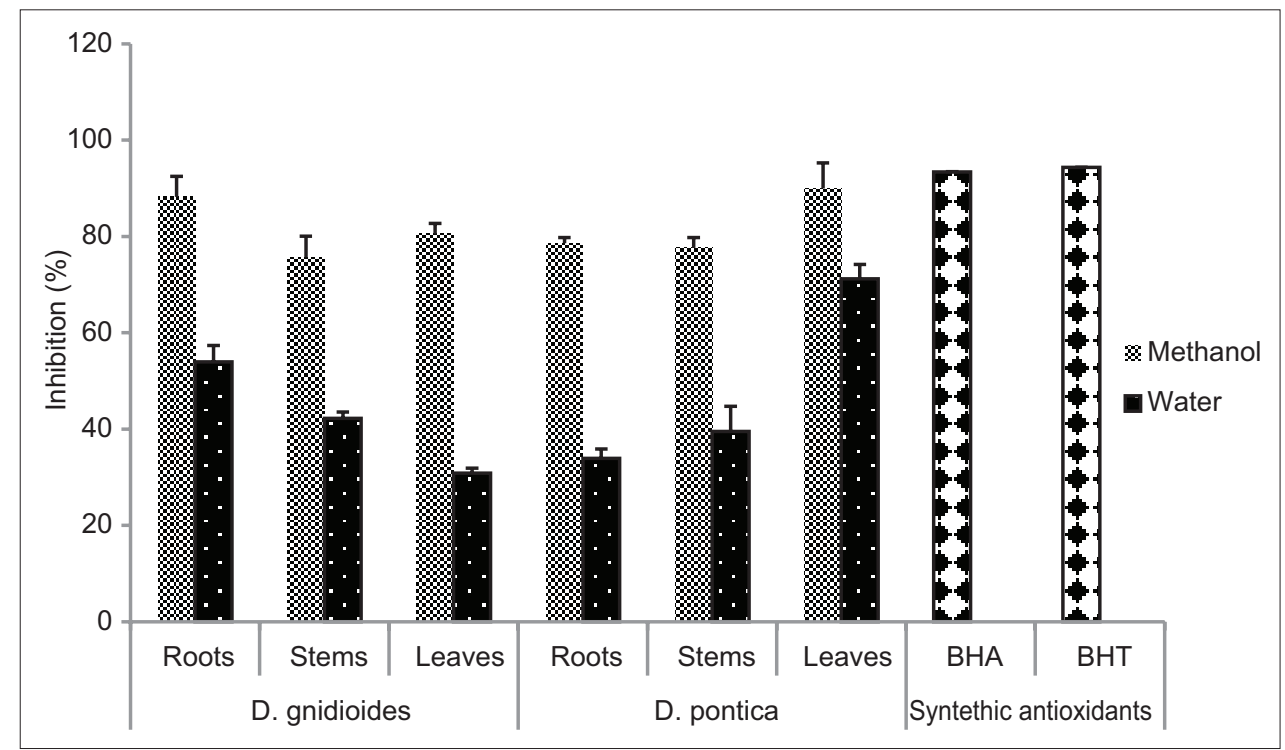

Fig 2. Antioxidant activity (\%) of Daphne extracts by and synthetic antioxidants by $\beta$-carotene bleaching method (Values expressed are means \pm S.D. of three parallel measurements).

(ethanol and methanol) of D. oleoides subp. oleoides and D. serica (Zengin et al., 2013).

\section{Reducing power assays}

Reducing power assays are often used as an indicator of electron-donating activity, which are an important mechanism of antioxidant compounds, especially phenolics. Therefore, potassium ferricyanide and CUPRAC methods were applied to evaluate reducing power potentials of Daphne extracts. Table 2 shows the reducing power of Daphne extracts using the potassium ferricyanide reducing method. The results showed that all extracts have a ferric reducing power in a dose-dependent manner. The highest activity was noted for leaves of $D$. pontica extracts which had ferric reducing power approximately 5 times greater than that water extract of leaves of $D$. gnidioides. Consistent with this, Zengin et al. (2013) reported that methanol extract of $D$. serica had the highest ferric reducing power activity in other extracts (hexan, etylacetate and ethanol). However, the reducing activities of all extracts were lower than BHA and BHT. The absorbance of BHA and BHT were 2.225 and 1.827 at concentration of $0.2 \mathrm{mg} \mathrm{mL}^{-1}$, respectively. As shown in Table 2, cupric reducing power activity of the extracts was dependent on the extract concentration. 
Sanda, et al.: Antioxidant potential of two Daphne species from Turkey

Table 3: Correlation analysis results of all Daphne extracts obtained for different antioxidant assays

\begin{tabular}{lccccccc}
\hline & TPC & TFC & TAC & DPPH & Ferric reducing power & Cupric reducing power & Inhibition (\%) \\
TPC & 1 & 0.071 & 0.430 & 0.811 & 0.707 & 0.805 & 0.542 \\
TFC & & 1 & -0.583 & 0.384 & 0.476 & 0.345 & 0.369 \\
TAC & & & 1 & 0.243 & 0.135 & 0.346 & 0.841 \\
DPPH & & & & 1 & 0.978 & 0.890 & 0.819 \\
Ferric reducing power & & & & & 1 & 1 & 0.141 \\
Cupric reducing power & & & & & & & 0.312 \\
\hline
\end{tabular}

The highest cupric reducing power was obtained for water extract of leaves of $D$. pontica and the lowest for methanol extract of stems of $D$. pontica.

\section{Principal Component Analysis (PCA) and correlation analysis}

It would be interesting to examine the correlations between antioxidant activities assays applied in the present work. For this reason, correlation analysis was applied to the data obtained by antioxidant assays and the results are presented in Table 3. High correlations were obtained between DPPH and ferric reducing power as well as with cupric reducing power $(\mathrm{p}<0.05)$. TPC is significantly correlated with DPPH radical scavenging activity, ferric and cupric reducing power. Therefore, phenolic compounds are the major contributors of antioxidant potential. In accordance with our results, many authors observed the strongest correlation between the total phenolic content and antioxidant capacity methods (Egea et al., 2010; Erkan et al., 2011; Sahreen et al., 2010) Ferric reducing power activities were more associated with cupric reducing power activities than inhibition activity of linoleic acid oxidation. Good correlation was observed among total antioxidant capacity assays, namely phosphomolybdenum and $\beta$-carotene/linoleic acid assays $(p<0.05)$. Conversely, a weak correlation was found among TFC and antioxidant capacity assays (DPPH, ferric and cupric reducing power). Similarly, some authors found weak correlation between antioxidant assays and TFC of several plant extracts (Muanda et al., 2011; Saeed et al., 2012). Principal component analysis (PCA) was also used evaluate the correlation among antioxidant capacity assays (Fig. 3). The loading of first and second principle components (PC1 and PC2) accounted for 55.83\% and $32.03 \%$ of the variance, respectively. PC1 was heavily loaded on TPC, DPPH, cupric and ferric reducing power assays, whereas PC2 was loaded on TFC and total antioxidant activity (TAC and inhibition activity). Similarly, Keles et al. (2011) showed that DPPH, phenolic and reducing power were heavily loaded on Factor 1 in their PCA, when methanolic extracts of wild edible mushrooms were analyzed.

\section{CONCLUSION}

The extracts of two Daphne species exhibited good but different levels of antioxidant activity in all in vitro

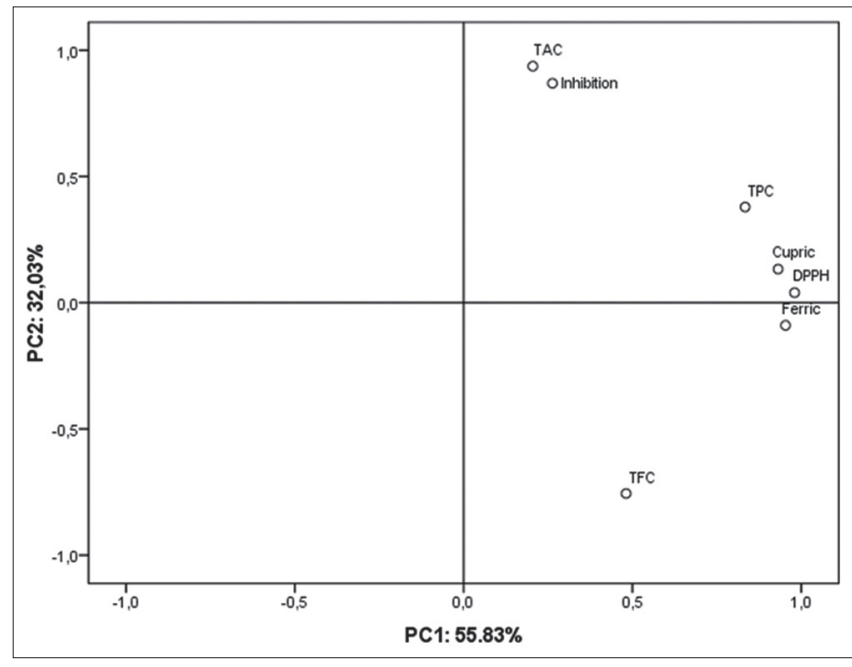

Fig 3. Principal component analysis results of TPC, TFC, TAC, DPPH, Inhibition ( $\beta$-caroten/linoleic acid assay), Cupric and Ferric Reducing Powers.

models. Both methanol and water extracts of D. pontica leaves showed lower $\mathrm{IC}_{50}$ values and had higher level of total phenolic content in comparison with other Daphne extracts. Our study is the first report on the in vitro antioxidant properties of the methanol and water extracts prepared from different parts (root, stem and leaves) of Daphne species. From these results, Daphne species studied can be used as accessible source of natural antioxidants and are useful as potential food supplements. In the future efforts will be made to identify the main components responsible for the antioxidant effect in Daphne extracts.

\section{ACKNOWLEDGEMENTS}

This study was supported financially as a project (11401068). The authors thank Selcuk University Scientific Research Foundation (BAP) for providing financial support for this study. The authors also want to thank Dr. Rajnish Gupta for proofreading the present manuscript.

\section{Author contributions}

M. A. S. and G. Z. made amajor contribution to the paper. A. A and Y. S. C. was involved in overall planning and supervision. 


\section{REFERENCES}

Akrout, A., L. A. Gonzalez, H. Eljani and P. C. Madrid. 2010. Antioxidant and antitumor activities of Artemisia campestris and Thymelaea hirsuta from southern of Tunisia. Food. Chem. Toxicol. 49: 342-347.

Apak, R., K. Guclu, M. Ozyurek, S. E. Karademir and E. Ercag. 2006. The cupric ion reducing antioxidant capacity and polyphenolic content of some herbal teas. Int. J. Food Sci. Nutr. 57: 292-304.

Apak, R., K. Guclu, M. Ozyurek and S. E. Karademir. 2004. Novel total antioxidant capacity index for dietary polyphenols and vitamins $\mathrm{C}$ and $\mathrm{E}$, using their cupric ion reducing capability in the presence of neocuproine: CUPRAC method. J. Agric. Food. Chem. 52: 7970-7981.

Arvouet-Grand, A., B. Vennat, A. Pourrat and P. Legret. 1994. Standardisation d'un extrait de propoliset identification des principaux constituants. J. Pharm. Belg. 49: 462-468.

Bekir, J., M. Mars, J. P. Souchard and J. Bouajila. 2013. Assessment of antioxidant, anti-inflammatory, anti-cholinesterase and cytotoxic activities of pomegranate (Punica granatum) leaves. Food. Chem. Toxicol. 55: 470-475.

Burda, S. and W. Oleszek. 2001. Antioxidant and antiradical activities of flavonoids. J. Agric. Food. Chem. 49: 2774-2779.

Da Silva, C. H. T., T. J. S. Sobrinho, V. T. N. Castro, D. C. A. Lima and E. L. C. Amorim. 2011. Antioxidant capacity and phenolic content of Caesalpinia pyramidalis Tul. and Sapium glandulosum (L.) Morong from North Eastern Brazil. Molecules. 16: 4728-4739.

Dapkevicius, A., R. Venskutonis, T. A. Van Beek and P. H. Linssen. 1998. Antioxidant activity of extracts obtained by different isolation procedures from some aromatic herbs grown in Lithuania. J. Sci. Food Agric. 77: 140-146.

Egea, I., P. Sanchez-Bel, F. Romojaro and M. T. Pretel. 2010. Six edible wild fruits as potential antioxidant addivites or nutritional supplements. Plant. Food. Hum. Nutr. 65: 121-129.

Erkan, N., S. Akgonen, S. Ovat, G. Goksel and E. Ayranci. 2011. Phenolic compounds profile and antioxidant activity of Dorystoechas hastate L. Boisset Heldr. Food. Res. Int. 44: 3013-3020.

Fernandez-Agullo, A., E. Pereira, M. S. Freire, P. Valentao, P. B. Andrade, J. Gonzalez-Alvarez and J. A. Pereira. 2013. Influence of solvent on the antioxidant and microbial properties of walnut (Juglans regia L.) green husk extracts. Indian. Crop. Prod. 42: 126-132.

Grieve, M. and C. F. Leyel. 1967. A Modern Herbal, the Medicinal, Culinary, Cosmetics and Economic Properties, Cultivation and Folklore of Herbs, Grasses, Fungi; Shrubs and Trees, 2. Herner Publishing Co., New York.

Ito, N., M. Hirose, S. Fukushima, H. Tsuda, T. Shirai and M. Tatematsu. 1986. Studies on antioxidants: Their carcinogenic and modifying effects on chemical carcinogenesis. Food. Chem. Toxicol. 24: 1071-1082.

Keles, A., I. Koca and H. Genccelep. 2011. Antioxidant properties of wild edible mushrooms. Food. Process. Technol. 2: 1-6.

Kim, S. I., K. H. Sim and H. Choi. 2010. A comparative study of antioxidant activity in some Korean medicinal plant used as food materials. Mol. Cell. Toxicol. 6: 279-285.

Magalhaes, L. M., M. A. Segundo, S. Reis and J. L. F. C. Lima. 2008. Methodological aspects about in vitro evaluation of antioxidant properties. Anal. Chim. Acta. 613: 1-19.

Muanda F., D. Kone, A. Dicko, R. Soulimani and C. Younos. 2011. Phytochemical composition and antioxidant capacity of three malian medicinal plant parts. Evid Based. Complement. Altern. 2011: 1-8.
Nabavi, S. M., M. A. Ebrahimzadeh, S. F. Nabavi, M. Fazelian and B. Eslami. 2009. In vitro antioxidant and free radical scavenging activity of Diospyros lotus and Pyrus boissieriana growing in Iran. Pharmacogn. Mag. 4: 123-127.

Oyaizu, M. 1986. Studies on products of browning reactions: Antioxidative activities of browning reaction prepared from glucosamine. Jpn. J. Nutr. 44: 307-315.

Pineli, L. L. O., C. L. Moretti and M. D. Chiarello. 2012. Quality, bioactive compounds and antioxidant activity of strawberries grown in the Brazilian savannah and stored at different temperatures. J. Food. Agric. Environ. 12: 165-171.

Prieto, P., M. Pineda and M. Aguilar. 1999. Spectrophotometric quantitation of antioxidant capacity through the formation of a phosphor molybdenum complex: Specific application to the determination of vitamin E. Anal. Biochem. 269: 337-341.

Saeed, N., M. R. Khan and M. Shabbir. 2012. Antioxidant activity, total phenolic and total flavonoid contents of whole plant extracts Torilis leptophylla L. BMC complem. Altern. Med. 12: 221-232.

Sahreen, S., M. R. Khan and R. A. Khan. 2010. Evaluation of antioxidant activities of various solvent extracts of Carissa opaca fruit. Food. Chem. 122: 1205-1211.

Sarikurkcu, C., K. Arisoy, B. Tepe, A. Cakir, G. Abali and E. Mete. 2009. Studies on the antioxidant activity of essential oil and different solvent extracts of Vitex agnus-castus L. fruits from Turkey. Food. Chem. Toxicol. 47: 2479-2483.

Sezik, E., E. Yesilada, G. Honda, T. Takaishi, Y. Takeda and T. Tanaka. 2001. Traditional medicine in Turkey X. Folk medicine in Central Anatolia. J. Ethnopharmacol. 75: 95-115.

Sherwin, E. R., A. L. Branen, P. M. Davidson and S. Salminen. 1990. Food Additivites. Marcel Dekker, New York, USA. p. 139-193.

Slinkard, K. and V. L. Singleton. 1977. Total phenol analyses: Automation and comparison with manual methods. Am. J. Enol. Vitic. 28: 49-55.

Tan, K. 1982. Flora of Turkey and the East Aegean Islands. Vol. 7. University Press, Edinburgh. p. 521-526.

Toullec, A., D. Gerald, G. Despouy, M. Bourachot, S. Cardon, M. Lefort, G. Richardson, M. C. Rigaill, C. Parrini, D. Lucchesi, M. H. Bellanger, T. Stern, X. Dubois, O. Sastre-Garau, Delattre, A. Vincent-Salomon and F. Mechta-Grigoriou. 2010. Oxidative stress promotes myofibroblast differentiation and tumour spreading. EMBO. Mol. Med. 2: 211-230.

Vignoli, J. A., D. G. Bassoli and M. T. Benassi. 2011. Antioxidant activity, polyphenols, caffeine and melanoidins in soluble coffee; the influence of processing conditions and raw material. Food. Chem. 124: 863-868.

Yang, Y. C. 1991. Traditional Tibetan Medicines. Qinghai People's Press, Xining. p. 427-429.

Yesilada, E., E. Sezik, G. Honda, Y. Takaishi, Y. Takeda and T. Tanaka. 1999. Traditional medicine in Turkey IX. Folk medicine in NorthWest Anatolia. J. Ethnopharmacol. 64: 195-210.

Zengin, G., T. Arkan, A. Aktumsek, G. O. Guler and Y. S. Cakmak. 2012. A study on antioxidant capacities and fatty acid compositions of two Daphne species from Turkey: New sources of antioxidants and essential fatty acids. J. Food. Biochem. 37: 646-653.

Zhang, Q., N. Ye, W. Sun, K. Zhang and J. Jiang. 2008. Phytochemical investigation of Daphne giraldii Nitsche (Thymelaeaceae). Biochem. Syst. Ecol. 36: 63-67.

Zhang, W., W. D. Zhang, R. H. Liu, Y. H. Shen, C. Zhang, H. S. Cheng, P. Fu and L. Shan. 2006. Two new chemical constituents from Daphne odora Thunb.var. marginata. Nat. Prod. Res. 20: 1290-1294. 